\title{
PRACTICE
}

\section{Diagnosis and treatment of dementia: 3 . Mild cognitive impairment and cognitive impairment without dementia}

\author{
Howard Chertkow MD, Fadi Massoud MD, Ziad Nasreddine MD, Sylvie Belleville PhD, Yves Joanette PhD, \\ Christian Bocti MD, Valérie Drolet BSc, John Kirk MD, Morris Freedman MD, Howard Bergman MD
}

\section{ABSTRACT}

Background: Mild cognitive impairment and cognitive impairment, no dementia, are emerging terms that encompass the clinical state between normal cognition and dementia in elderly people. Controversy surrounds their characterization, definition and application in clinical practice. In this article, we provide physicians with practical guidance on the definition, diagnosis and treatment of mild cognitive impairment and cognitive impairment, no dementia, based on recommendations from the Third Canadian Consensus Conference on the Diagnosis and Treatment of Dementia, held in March 2006.

Methods: We developed evidence-based guidelines using systematic literature searches, with specific criteria for study selection and quality assessment, and a clear and transparent decision-making process. We selected studies published from January 1996 to December 2005 that had mild cognitive impairment or cognitive impairment, no dementia, as the outcome. Subsequent to the conference, we searched for additional articles published between January 2006 and January 2008 . We graded the strength of evidence using the criteria of the Canadian Task Force on Preventive Health Care.

Results: We identified 2483 articles, of which 314 were considered to be relevant and of good or fair quality. From a synthesis of the evidence in these studies, we made 16 recommendations. In brief, family physicians should be aware that most types of dementia are preceded by a recognizable phase of mild cognitive decline. They should be familiar with the concepts of mild cognitive impairment and of cognitive impairment, no dementia. Patients with these conditions should be closely monitored because of their increased risk for dementia. Leisure activities, cognitive stimulation and physical activity could be promoted as part of a healthy lifestyle in elderly people and those with mild cognitive impairment. Vascular risk factors should be treated optimally. No other specific therapies can yet be recommended.

Interpretation: Physicians will increasingly see elderly patients with mild memory loss, and learning an approach to diagnosing states such as mild cognitive impairment is now warranted. Close monitoring for progression to dementia, promotion of a healthy lifestyle and treatment of vascular risk factors are recommended for the management of patients with mild cognitive impairment.

Une version française de ce résumé est disponible à l'adresse www.cmaj.ca/cgi/content/full/I78/Io/I273/DCI

CMAJ 2008;178(10):1273-85

\section{The case}

Mr. W's wife and children have noticed his decreasing memory over the past year. This 66-year-old working executive is completely functional other than making lists when he goes shopping, but he is starting to worry. "He forgets details of conversations we have," his wife complains. His medical history is unremarkable except for hypertension, for which he takes ramipril and hydrochlorothiazide. He also takes $80 \mathrm{mg}$ of acetylsalicylic acid daily, and diazepam for sleep on a regular basis. He gets little exercise, but he is in a challenging and enjoyable position at work. Findings on physical examination are unremarkable. The results of the neurologic examination are normal aside from cognition. On brief cognitive testing with

From the Bloomfield Centre for Research in Aging, Lady Davis Institute for Medical Research, Sir Mortimer B. Davis-Jewish General Hospital (Chertkow, Bocti, Bergman), McGill University, Montréal, Que.; the Division of Geriatric Medicine, Department of Medicine, Sir Mortimer B. Davis-Jewish General Hospita (Chertkow, Bocti, Bergman, Kirk), McGill University; the Department of Neurology and Neurosurgery (Chertkow), McGill University; Centre de recherche, Institut Universitaire de Gériatrie de Montréal and Université de Montréal (Chertkow, Belleville, Joanette, Drolet), Montréal, Que.; Département de médecine, service de neurologie (Nasreddine), Hôpital Charles LeMoyne, Université de Sherbrooke, Sherbrooke, Que.; Service de gériatrie, Département de médecine (Massoud), Centre hospitalier de l'Université de Montréal; the Department of Neurology (Bocti), Maisonneuve Rosemont Hospital, Université de Montréal, Montréal, Que.; and the Department of Medicine (Neurology), Mount Sinai Hospital and University of Toronto, and the Division of Neurology and Rotman Research Institute, Baycrest Centre for Geriatric Care (Freedman), Toronto, Ont.

This series is based on recommendations from the Third Canadian Consensus Conference on the Diagnosis and Treatment of Dementia.

Series editor: Howard Chertkow MD, Department of Neurology, McGill University and the Bloomfield Centre for Research in Aging, Lady Davis Institute, Sir Mortimer B. Davis-Jewish General Hospital, Montréal, Que. 
the Mini-Mental State Examination, Mr. W has a score of 27 out of 30 , he is oriented, and his concentration (serial 7 subtractions) is normal. He copies a pentagon well. His delayed verbal memory, however, is quite impaired, and he recalls only 1 of 3 words in a list after a 1-minute delay. He asks you if this is the beginning of Alzheimer disease, whether he should retire and what he can do to prevent any further deterioration. You suspect he meets the criteria for mild cognitive impairment. What investigations and treatment should be initiated?

$\mathrm{B}$ etween $25 \%$ and $75 \%$ of elderly people report that their memory is worse than it was when they were younger, depending on how the question is phrased. ${ }^{1,2}$ Almost all of these people worry that this change in memory might represent the beginning of Alzheimer disease or another type of dementia. Indeed, public opinion polls have shown that concerns about Alzheimer disease are among the 3 leading worries of elderly people. ${ }^{3}$ In the past, physicians tended to offer blanket reassurances that "you are normal." Although the majority of elderly people who note memory changes will not go on to have dementia, dementia does develop in $8 \%$ of elderly people,${ }^{4}$ so such reassurances may not be appropriate.

In this article, we focus on the "grey zone" between no dementia and dementia. We provide physicians with practical guidance on the definition, diagnosis and treatment of mild cognitive impairment and cognitive impairment with no dementia, based on recommendations from the Third Canadian Consensus Conference on the Diagnosis and Treatment of Dementia (Box I). A description of the process used to generate the recommendations is provided in the first article of the series $^{6}$ and in an online appendix accompanying this article (available at www.cmaj.ca/cgi/content/full/178/10/I273/DC2). Published background papers provide details of the evidencebased reviews on which the recommendations are based.,

\section{The concept of mild cognitive impairment}

Using the accepted published criteria, ${ }^{6,9,10}$ most physicians feel fairly confident now in diagnosing Alzheimer disease and other types of dementia. Patients who do not have dementia but who may not be "normal" remain diagnostic challenges. In fact, the concept of "normality" in an elderly person is itself controversial. Although most elderly people note subtle changes in their memory and cognition since youth, most feel that their memory performance and daily functioning is similar to that of others their age. The majority of experts view this as normal "cognitive aging" and that normality must be determined with respect to a particular age group..$^{11-13}$ This concept of normality does not require the total absence of unrelated diseases (e.g., in a survey of 2590 adults in the United States, $19 \%$ of men and $23 \%$ of women aged 65 years or more reported taking at least 5 prescription medications ${ }^{14}$ ) but, rather, performance at an equivalent level to their peer group.

In the large, population-based Canadian Study of Health and Aging, elderly people were classified as having one of the following conditions: no cognitive loss; cognitive impairment, no dementia; or dementia. ${ }^{4,15}$ The study defined cognitive im- pairment, no dementia, as the presence of objective cognitive impairment in any domain tested, with performance falling between the 2 poles of normality and dementia. Overall, $\mathrm{I} 6.8 \%$ of elderly people were found to fall into this category. ${ }^{16,17}$ These individuals showed an increased risk of eventual dementia (about 50\% after a 5-year follow-up period) and death. ${ }^{18}$

The label "cognitive impairment, no dementia," has the benefit of requiring physicians to simply conclude that there is cognitive impairment, without having to consider what the degree of decline is, whether functional impairment is present or what the underlying causes might be. A number of limitations, however, are inherent in using this term. One drawback is that a person might be considered as having cognitive impairment, no dementia, because of memory loss due to an underlying condition (e.g., lifelong static brain damage, mental retardation or schizophrenia) that would be obvious to the treating physician or specialist. In this case, the prognosis and approach to the diagnosis of cognitive impairment, no dementia, would not be as relevant to the treating family physician or specialist, who is focused instead on the patient's complaint of a new decline in memory. When the label was applied in a cohort of patients referred to memory clinics in Canada, the causes appeared quite heterogeneous,${ }^{19}$ including amnestic, vascular, psychiatric, neurologic, metabolic and mixed.

A more widespread term currently used to characterize this grey zone between normality and dementia is "mild cognitive impairment." ${ }^{20-22}$ This clinical label is applied to elderly people with short- or long-term memory impairment who have no significant daily functional disability. The initial criteria for mild cognitive impairment requires a subjective report of cognitive decline from a former level, gradual in onset, and present for at least 6 months. This subjective report is supplemented by objective evidence of decline in memory and learning on brief or extensive cognitive testing. Other cognitive domains remain generally intact. ${ }^{23}$ There is no clear delineation as to how the presence of memory loss is to be established, but the presence of objective signs is emphasized. Later work enlarged the definition so that other domains besides memory might show impairment. In all cases, this term excludes people who have significant depression, delirium, mental retardation or other psychiatric disorders that are likely responsible for the impairment. If the memory loss is severe and accompanied by significant functional impairment and other cognitive impairments, the patient meets the clinical criteria for dementia, not mild cognitive impairment.

The concept of mild cognitive impairment is intended to capture and classify patients like Mr. W, described at the beginning of the article. He seems to have a cognitive problem that one would be loathe to label as "normal," and yet it is not severe enough to qualify as dementia. The differences in diagnostic criteria between mild cognitive impairment and cognitive impairment, no dementia, are provided in Table I.

\section{Vascular factors}

Many people with mild cognitive impairment have vascular risk factors. In some cases, imaging reveals silent cerebral infarcts that amplify the effects of any degenerative brain disease. In 
Box 1: Recommendations for the definition, diagnosis and treatment of mild cognitive impairment and cognitive impairment, no dementia*

\section{Definition}

- Physicians should be aware that most dementias may be preceded by a recognizable phase of mild cognitive decline. Physicians should be familiar with the concept of mild cognitive impairment (or cognitive impairment, no dementia) as a high-risk state for decline and dementia [grade $B$ recommendation, level 3 evidence].

- There is currently inadequate evidence to recommend one term or label ("mild cognitive impairment" or "cognitive impairment, no dementia") over another [grade B recommendation, level 3 evidence].

\section{Diagnosis}

- In cases where there is suspicion of cognitive impairment or concern about the patient's cognitive status, and the Mini-Mental State Examination score is in the normal range (24-30), tests such as the Montréal Cognitive Assessment or DemTect could be administered. These tests would help to demonstrate objective cognitive loss [grade B recommendation, level 2 evidence].

- There is fair evidence that the addition of in-depth neuropsychological testing can be recommended to aid in the confirmation of the diagnosis [grade $B$ recommendation, level 2 evidence].

\section{Risk of progression to dementia}

- There is inadequate evidence to advise patients with mild cognitive impairment and their families that the patient is already showing signs of dementia, or to treat mild cognitive impairment as equivalent to dementia [grade $\mathrm{C}$ recommendation, level 2 evidence].

- There is fair evidence that physicians should closely monitor individuals who have mild cognitive impairment or cognitive impairment, no dementia, because of the known increased risk of dementia that has been documented [grade B recommendation, level 2 evidence].

\section{Nonpharmacologic treatment}

\section{Cognitive interventions}

- The evidence at the present time is insufficient to conclude that organized cognitive intervention is beneficial for preventing progression in patients with mild cognitive impairment or warrants prescription [grade C recommendation, level 1 evidence].

- There is fair evidence that physicians and therapists should promote engagement in cognitive activity as part of an overall "healthy lifestyle" formulation for elderly individuals with and without memory loss [grade B recommendation, level 2 evidence].

\section{Physical exercise}

- Current evidence is insufficient to conclude that a specific program of physical training warrants prescription in patients with mild cognitive impairment in order to prevent progression to dementia [grade C recommendation, level 3 evidence].

- There is fair evidence that physicians and therapists should promote physical activity, at an intensity level that is adapted to the person's overall physical capacities, as part of a "healthy lifestyle" for older individuals with and without memory loss [grade B recommendation, level 2 evidence].

\section{Treatment of vascular risk factors}

- As vascular risk factors and comorbidities impact on the development and expression of dementia, they should be screened for and treated optimally in patients with mild cognitive impairment [grade B recommendation, level 2 evidence].

- Treating hypertension: There is good evidence to treat systolic hypertension (> $160 \mathrm{~mm} \mathrm{Hg}$ ) in all older individuals. In addition to reducing the risk of stroke, the incidence of dementia may be reduced. The target systolic blood pressure should be $140 \mathrm{~mm} \mathrm{Hg}$ or less [grade A recommendation, level 1 evidence].

- There is some evidence that treating hypertension may prevent further cognitive decline associated with cerebrovascular disease. There is no compelling evidence that one class of agent is superior to another; calcium-channel blockers or angiotensinconverting-enzyme (ACE) inhibitors may be considered [grade B recommendation, level 1 evidence].

- Antiplatelet therapy with acetylsalicylic acid: There is currently no evidence to support the use of acetylsalicylic acid to specifically treat dementia associated with cerebrovascular disease [grade $C$ recommendation, level 3 evidence]. Acetylsalicylic acid or other antiplatelet therapies should be used for the prevention of recurrent ischemic stroke in appropriate patients ${ }^{5}$ [grade A recommendation, level 1 evidence].

\section{Pharmacologic treatment}

- There is currently insufficient evidence to recommend the use of cholinesterase inhibitors in mild cognitive impairment [grade $C$ recommendation, level 1 evidence].

- There is currently fair evidence to recommend against the use of nonsteroidal anti-inflammatory drugs in mild cognitive impairment [grade $\mathrm{D}$ recommendation, level 1 evidence].

- There is currently fair evidence to recommend against the use of estrogen replacement therapy in mild cognitive impairment [grade $\mathrm{D}$ recommendation, level 1 evidence].

- There is currently fair evidence to recommend against the use of ginkgo biloba or vitamin $\mathrm{E}$ in mild cognitive impairment [grade D recommendation, level 1 evidence]. 
others, the patient may have had a series of silent or clinical strokes that have a cumulative effect on their cognition, and the brain shows none of the changes indicative of Alzheimer disease. In such cases, we might use the term "vascular cognitive impairment" rather than mild cognitive impairment. The concept of vascular cognitive impairment has been introduced to emphasize the high prevalence of cognitive impairment when there is vascular damage to the brain. ${ }^{24}$ The term encompasses all degrees of severity of cognitive deficits resulting from vascular disease: some patients would not be considered to have dementia according to current definitions, others would meet the criteria for vascular dementia, and still others would be considered to have dementia, which would best be labelled as mixed Alzheimer disease and cerebrovascular disease. ${ }^{25-27}$ The inclusion of the mildest form of cognitive impairment will enable patients and health care professionals to optimize preventive strategies before the stage of clear dementia is attained. In all of these individuals, there is good evidence that hypertension should be recognized and treated appropriately (see the section "Treatment of vascular factors"). The evidence for treatment of other risk factors is less compelling.

\section{Controversies in mild cognitive impairment}

Mild cognitive impairment is still a controversial clinical concept, with several different diagnostic criteria and definitions of memory loss being used. Depending on the diagnostic criteria used, the prevalence and incidence of mild cognitive impairment vary considerably. ${ }^{17,28}$ Because of these uncertainties, some have opposed adoption of the term "mild cognitive impairment" for clinical use. ${ }^{29}$ However, the growing use of the term as a diagnostic entity has empowered physicians and patients and has given them a more accurate view of the nature of the patient's mild memory loss than was previously possible. ${ }^{30,31}$ In addition, recognition of the condition at this stage may prove to be the optimum point at which to intervene with preventive therapies when they become available. ${ }^{32}$ Mild cognitive impairment will increasingly become a label used by neurologists, geriatricians and family physicians who have elderly patients with cognitive impairment.
One uncertainty is whether patients with mild depression should be excluded from consideration as having mild cognitive impairment. Some studies have shown that depression is present in up to $60 \%$ of patients with mild cognitive impairment who go on to have Alzheimer disease, and the presence of depression may in fact be a useful prognostic sign in patients with mild cognitive impairment. ${ }^{33}$

Another challenge is the assessment of "significant impairment in functional ability," which is one of the criteria for dementia, and hence important in separating mild cognitive impairment from dementia. Unfortunately, there is little agreement on the criteria for the evaluation of functional ability, and no agreement on what "significant" functional impairment entails. About $31 \%$ of patients with mild cognitive impairment probably have subtle functional changes ${ }^{34}$ and one might even think the need to maintain written lists is a functional change. The key distinction for diagnosis of mild cognitive impairment is that the changes should affect only higher functions and not represent "significant impairment," although this is crudely defined. The most sensitive questions for detecting functional impairment appear to be those that ask patients about whether they are maintaining their hobbies, are able to handle complex financial affairs, are able to use new equipment and tools, are finding themselves repeating questions, or are forgetting the month and year. ${ }^{35}$ There is also controversy about the best way to objectively measure memory loss, whether by means of brief cognitive testing or a full neuropsychological evaluation.

For all these reasons, it is usual to encounter subtle but significant variability in patients with mild cognitive impairment. ${ }^{36}$ Mild cognitive impairment is perhaps best viewed as a somewhat heterogeneous clinical syndrome that for some patients may be a prodrome for dementia (Figure I).

\section{Approach to diagnosis}

Mild cognitive impairment should be detected and diagnosed because people with this condition are at increased risk for Alzheimer disease or other types of dementia compared with similarly aged individuals in the general population. ${ }^{22}$ There have been no studies that have validated a particular diagnos-

Table 1: General diagnostic criteria for mild cognitive impairment and for cognitive impairment, no dementia

\begin{tabular}{|c|c|c|}
\hline Feature & $\begin{array}{l}\text { Mild cognitive } \\
\text { impairment }\end{array}$ & $\begin{array}{l}\text { Cognitive impairment, } \\
\text { no dementia }\end{array}$ \\
\hline $\begin{array}{l}\text { Subjective complaint of memory loss by patient } \\
\text { or family member }\end{array}$ & Yes & Not required \\
\hline $\begin{array}{l}\text { Objective evidence of impairment in memory } \\
\text { or other cognitive domain }\end{array}$ & $\begin{array}{l}\text { Yes, based on results of brief cognitive } \\
\text { testing or neuropsychological testing }\end{array}$ & $\begin{array}{l}\text { Yes, based on results of standardized } \\
\text { neuropsychological testing }\end{array}$ \\
\hline $\begin{array}{l}\text { History of decline from previously normal level of } \\
\text { function (if not due to brain disease) }\end{array}$ & Yes & Not required \\
\hline Preservation of basic daily functioning & Yes & Not specified \\
\hline $\begin{array}{l}\text { Other obvious medical, neurologic or psychiatric } \\
\text { explanation for memory loss absent }\end{array}$ & Yes & Not specified \\
\hline $\begin{array}{l}\text { Cognitive impairment does not meet criteria } \\
\text { for dementia }\end{array}$ & Yes & Yes \\
\hline
\end{tabular}

Sources: references 4, 15, 21 and 22 . 
tic approach. Some physicians suggest that the process for diagnosing mild cognitive impairment should be the same as that for diagnosing dementia, which includes history-taking and physical examination, brief cognitive testing, and laboratory tests to look for reversible causes of memory loss. ${ }^{10}$ Although neuroimaging with computed tomography or magnetic resonance imaging has been extensively investigated for its possible role in establishing a prognosis, we lack studies demonstrating that it is necessary for a family physician to carry out imaging in patients with mild cognitive impairment.

Until 200I, there were no specific brief cognitive tests to detect mild cognitive impairment. Although the Mini-Mental State Examination was considered useful, it had low sensitivity to detect mild cognitive impairment. ${ }^{37}$ Since that time, several brief instruments have been developed to help screen for mild cognitive impairment. Although they have not been compared in studies, 2 of the tests - the DemTect ${ }^{38}$ and the the Montréal Cognitive Assessment ${ }^{39}$ - have shown promising results in well-designed studies based on prespecified criteria for mild cognitive impairment. ${ }^{37}$

The Montréal Cognitive Assessment, developed by some of the authors of this article, takes IO-I5 minutes to administer and evaluates the following domains: delayed recall, verbal fluency, visuospatial skills, clock drawing, executive functions, calculation, abstraction, language, orientation, attention and concentration. In a validation study involving 277 French- and English-speaking participants recruited from a memory clinic, the test achieved a sensitivity of $90 \%$ and specificity of $87 \%$ to detect mild cognitive impairment in patients and distinguish them from normal controls. The positive predictive value was $89 \%$, and the negative predictive value was $91 \%$. The Montréal Cognitive Assessment and instructions can be obtained by physicians free of charge at www.mocatest.org. The DemTect assesses word recall, number transcoding, semantic word fluency and digit span. In a validation study involving 363 English-speaking participants, the test achieved a sensitivity of $80 \%$ and specificity of $92 \%$ to detect mild cognitive impairment in patients and distinguish them from normal controls.

One important qualification of the Montréal Cognitive Assessment and DemTect is that neither has been fully validated in a family practice setting.

\section{Risk of progression to dementia}

In the opening case of this article, Mr. $\mathrm{W}$ asks if he has early signs of Alzheimer disease and whether his condition will get worse. His concern is understandable, since patients classi- fied as having mild cognitive impairment have a high rate of progression to dementia, particularly Alzheimer disease. Some others have pathological evidence of dementia with Lewy bodies or cerebral infarction. ${ }^{40}$ In most clinic-based studies of mild cognitive impairment, $40 \%-80 \%$ of patients who met the criteria for this condition were found to have Alzheimer disease during a 5-year follow-up, for an annual conversion rate of about I0\%-I5\%. ${ }^{28,41-47}$ The conversion rate is substantially lower in population-based samples. ${ }^{48}$ What is not known is whether all people with mild cognitive impairment will go on to have dementia. In a ro-year follow-up study in a memory clinic, Visser and colleagues found the risk of progression to dementia to be $48 \%$ among 64 patients with mild cognitive impairment. ${ }^{49}$ In a Canadian study involving 89 patients with mild cognitive impairment recruited in a memory clinic, no disease progression occurred in about $25 \%$, even Io years after onset of memory problems. ${ }^{50-52}$ The diagnostic category of mild cognitive impairment appears to contain many individuals who will go on to have Alzheimer disease or another type of dementia as well as a subgroup of people in whom no progression will occur and who may even be found to have no cognitive impairment at a second visit. ${ }^{42,43,45,46}$ It is best to view people with mild cognitive impairment as a group at high-risk for dementia. ${ }^{43-46,53}$

Is it possible to determine at initial presentation which people with mild cognitive impairment will go on to have Alzheimer disease in a limited period (e.g., 5 years)? There appear to be notable and measurable deficits in people in whom Alzheimer disease develops, a good number of years before the diagnosis is officially made on clinical grounds. ${ }^{54}$ Numerous attempts have been made to identify prognostic markers in mild cognitive impairment. Most involved rather small samples of patients followed for limited periods. ${ }^{55,56} \mathrm{~A}$ number of biomarkers, imaging techniques and neuropsychological tests are under investigation (Box 2), ${ }^{57-82}$ with promising results of their predictive utility. However, insuffi- 
cient evidence is available regarding their sensitivity, specificity, reproducibility and ease of use. Therefore, we cannot yet advocate their routine use for predicting progression to dementia in patients with mild cognitive impairment. Some combination of cognitive testing and imaging may, in the future, allow more accurate prediction. Until then, annual clinical follow-up is the best recommendation.

\section{Treatment}

The treatment of mild cognitive impairment has been the subject of a number of recent chapters and reviews. ${ }^{56,83}$ There have been relatively few randomized controlled trials of any therapy sufficient to rank as level I evidence. Nevertheless, there are a number of potential interventions, both nonpharmacologic and pharmacologic, that deserve to be addressed. Table 2 provides additional information on studies relevant to nonpharmacologic treatment of mild cognitive impairment. ${ }^{84-98}$

\section{Nonpharmacologic treatment}

\section{Treatment of exacerbating and comorbid conditions} There are a number of conditions that can exacerbate memory loss in mild cognitive impairment, or even produce mild cognitive impairment in an otherwise cognitively normal elderly individual. Attention to these factors is recommended, even in the absence of formal RCTs.

Patients with sleep disorders often present with memory loss, ${ }^{99}$ and this seems a reasonable factor to assess and

Box 2: Markers and tests under investigation to determine their ability in predicting the risk of progression from mild cognitive impairment to Alzheimer disease

\section{Biomarkers}

- $\beta$-Amyloid and tau protein levels in cerebrospinal fluid ${ }^{57}$

- Genetic markers: apolipoprotein E gene $(A P O E)^{58}$

- High homocysteine levels ${ }^{59}$

- High levels of low-density lipoprotein or a high ratio of low-density lipoprotein to high-density lipoprotein ${ }^{60}$

- Serum interleukin-6 $6^{61}$

- Olfactory dysfunction ${ }^{62,63}$

- Heme oxygenase-1 in blood ${ }^{64}$

Imaging techniques

- Hippocampal volume ${ }^{65}$

- Rate of change of global or hippocampal volume ${ }^{66,67}$

- Decreased focal brain function demonstrated with positron emission tomography or single photon emission computed tomgoraphy68-77

- Pattern of amyloid plaque deposition, as indicated with positron emission tomography using the Pittsburgh Compound-B $(\mathrm{PiB})$ radiotracer $^{78}$

\section{Neuropsychological tests}

- Batteries of several formal neuropsychological tests (particularly tests of delayed verbal recall and executive function $)^{79-82}$ treat. ${ }^{99-101}$ Referral for assessment of sleep apnea in a specialty sleep clinic is recommended if the patient reports a sleep problem.

The overlap between dementia and depression continues to be an important area, and untreated depression will exacerbate and amplify memory loss. ${ }^{102-106}$ If present, depression in mild cognitive impairment and early Alzheimer disease should be treated with appropriate nonpharmacologic and pharmacologic approaches.

Isolation has also been proposed as an exacerbating factor. An important study in the Kungsholmen district of Stockholm ${ }^{107}$ demonstrated that a poor or limited social network increased the risk of dementia by $60 \%$, and a significant gradient was found for increasing degrees of social connections. An extensive social network appears to protect against dementia. Clearly this requires a lifelong commitment to building social interactions, but this may be a modifiable risk, and patients with mild cognitive impairment should be encouraged to have social interactions. Nevertheless, the literature on all of these factors is meager, and no specific recommendations can be made on any of these items.

\section{Cognitive interventions}

Longitudinal cohort studies involving healthy elderly people have shown that engagement in stimulating cognitive activities (engaged lifestyle; novel and intellectually challenging activities) is associated with better memory and verbal abilities compared with people not engaging as much in such activities. ${ }^{86}$ Participation in intellectually stimulating and social activities in midlife has been associated with reduced risk of Alzheimer disease. ${ }^{90,91}$ One large-scale randomized controlled trial of cognitive interventions (training memory, cognitive processing speed or reasoning v. no training) was completed in a sample of 2832 healthy older adults. ${ }^{93}$ The results indicated improved performance following training in the cognitive domains that were targeted by the interventions. The positive effects (less decline in cognitive function and in complex daily activities) were sustained over a 2-year and even a 5-year follow-up, and the effect sizes were moderate to large. ${ }^{108}$ There is good evidence that cognitive training increases cognitive efficacy on target measures in healthy older adults.

Two nonrandomized studies and 2 randomized controlled trials, all with relatively small samples, reported that cognitive training was associated with long-term improvement in cognitive performance (working memory and verbal episodic memory) in people with mild cognitive impairment. ${ }^{95,96,98}$ Belleville and colleagues, ${ }^{97}$ in a study of a multifactorial program for memory training versus no training involving 28 participants with mild cognitive impairment, reported larger memory improvement in the trained group than in the group without training. Moderate to large effect sizes were observed for the training effect on target episodic memory measures.

Studies investigating the effect of cognitive interventions in mild cognitive impairment have provided encouraging findings. However, the effort required to implement such therapeutic measures is not trivial, and large-scale cognitive interventions would require considerable resources. Before this therapy can be recommended for widespread use, more re- 
search is required in the form of properly designed randomized controlled trials with larger samples. The evidence at present is insufficient to conclude that organized cognitive intervention is beneficial in preventing progression in mild cognitive impairment. In terms of general intellectual activity, we have alluded to population-based studies only, showing that participation in intellectually stimulating and social activities in midlife has been associated with reduced risk of Alzheimer disease. ${ }^{90,91}$ These data do not provide the same level of evidence as would come from randomized controlled trials of the effect of beginning such activities at age 65 , or when mild cognitive impairment is diagnosed, to prevent or delay progression to $\mathrm{Alz}$ heimer disease compared with controls. On the other hand, given that there is little or no harm associated with general engagement in stimulating cognitive activities, physicians and other health professionals can promote engagement in cognitive activities as part of an overall healthy lifestyle for elderly patients with and without memory loss (Box I). The data to date suggest that cognitive intervention is more efficient in people with relatively mild cognitive deficits (healthy older adults and people with mild cognitive impairment) than in people with mild dementia. Cognitive intervention is also more efficient when provided in structtured programs provided to small groups, which allows the therapist to adapt the approach to the individual needs and capacities of the participants.

\section{Physical activity}

Several longitudinal cohort studies involving elderly people without cognitive impairment at enrolment have indicated that physical exercise is associated with reduced cognitive decline and reduced risk of dementia. ${ }^{87,88}$ However, other studies have failed to show a protective effect of physical exercise on cognitive decline and dementia. ${ }^{109}$ Two recent metaanalyses of the impact of physical exercise programs on the cognitive function of older adults reported moderate effect sizes for exercise training on global cognitive scores, ${ }^{84,85}$ with a larger effect on tasks measuring executive control reported by Colcombe and Kramer. ${ }^{84}$ There are immense implications of such research in terms of potential public health measures to prevent dementia and cognitive decline. More randomized controlled trials are needed to assess the optimal forms of exercise training in older adults, particularly in terms of intensity and duration. Safety issues will also need to be better addressed. Finally, no studies have been carried out involving specifically people with mild cognitive impairment to assess the effect of physical training on their cognitive capacities and cognitive decline. Nevertheless, it is recommended that physicians and other health professionals may promote physical activity, at an intensity level that is adapted to the person's overall physical capacities, as part of a healthy lifestyle for older individuals with and without memory loss.

\section{Treatment of vascular risk factors}

Several epidemiologic studies have shown an association between vascular risk factors and cognitive impairment. ${ }^{110-113}$ Results from 3 clinical trials ${ }^{114-116}$ have supported the role of treatment of hypertension in reducing the risk of cognitive decline in elderly people without dementia, some of whom had mild cognitive impairment. The Syst-Europe randomized controlled trial ${ }^{144}$ involved $24 \mathrm{I} 8$ older people with isolated systolic hypertension and showed a 50\% decrease in cases of dementia after 2 years in the treatment group compared with the control group. By extrapolation of these results, if rooo hypertensive patients were treated with antihypertensive drugs for 5 years, I9 cases of dementia might be prevented. Another study of blood pressure reduction in elderly people with cerebrovascular disease resulted in significant but less impressive reduction in cognitive decline and dementia. ${ }^{115}$ The third clinical trial compared captopril and bendrofluazide in people with mild cognitive deficits. ${ }^{116}$ Patients with the best response to treatment in terms of reduction of their diastolic blood pressure showed significant improvement on 2 cognitive tests.

Findings from these 3 studies suggest that the reduction of blood pressure in elderly patients with hypertension who have mild cognitive impairment is not hazardous. The evidence that treating other vascular risk factors will reduce subsequent dementia is meager. Trials of primary prevention with statins, for instance, did not provide any evidence of benefit on cognitive function. ${ }^{117,118}$ We recommend treatment of vascular risk factors, including hypertension, as an effective means of preventing progression to dementia in patients with mild cognitive impairment (Box I).

\section{Pharmacologic treatment}

Several classes of drugs have been studied for the prevention of progression to dementia. These include cholinesterase inhibitors, nonsteroidal anti-inflammatory drugs, estrogen replacement therapy, ginkgo biloba and vitamin E. The studies have shown no benefit either in terms of clinically meaningful symptomatic benefit or prevention of progression to dementia in patients with mild cognitive impairment (Table 3). ${ }^{119-125}$ In a study of the cholinesterase inhibitor galantamine, mortality was increased in the treatment group compared with the control group. ${ }^{122}$ Details on the literature are available in reviews ${ }^{55,56,83}$ and the background papers for this article. ${ }^{7,8}$ Given the findings of these studies, we do not recommend the use of these medications for the treatment of mild cognitive impairment (Box I).

Other classes of drugs currently being studied include statins, cholesterol-lowering drugs, anti-amyloid drugs (e.g., $\beta$-secretase inhibitors, gamma-secretase inhibitors, glycosaminoglycan mimetics, amyloid immunotherapy) and ampakines.

\section{Knowledge gaps}

In this article, we have alluded to several gaps in our knowledge. The most fundamental of these is whether establishing "mild cognitive impairment" as a clinical diagnosis will improve our care of elderly patients and lead to better strategies for preventing dementia and whether it will increase a patient's anxiety. There are no studies to date that critically examine the psychological or social effects of using the label "mild cognitive impairment" in a clinical context. It is our clinical impression, however, that there are psychological benefits to a patient in being given a diagnosis of mild cognitive impairment, as opposed to being told (erroneously) that he or 
she is "normal" or that "the doctor doesn't know what it is."

We lack easy, reliable and useful tools for predicting which people with mild cognitive impairment will go on to have dementia. Large observational studies are required, and some are underway, to understand the complex factors involved in the evolution of mild cognitive impairment and the interplay of risk factors in the development to dementia. Paradoxically, mild cognitive impairment is a term that may be used less, or not at all, once reliable, inexpensive biomarker or physiologic tests become available. ${ }^{127}$

If mild cognitive impairment is to remain with us as a diagnosis, one limitation is the lack of standardization of how to apply this diagnosis in practice. For instance, there is little agreement on how to define "largely preserved function," or how physicians should assess function. For that matter, "sig- nificant impairment in function" (a basic component of the definition of dementia) remains poorly defined.

There is a need for longitudinal studies to validate any diagnostic approach. Currently, no accepted or recommended way to diagnose or screen for mild cognitive impairment exists. We lack studies, for instance, that demonstrate whether structural imaging will have an impact on the ultimate outcome of patients with mild cognitive impairment.

Larger trials are needed to determine the efficacy of all of the pharmacologic and nonpharmacologic interventions being considered. For instance, it has been shown that a poor or limited social network increases the risk of dementia substantially, but we do not know whether programs to increase the social interactions of elderly people would protect against the development of dementia.

Table 2: Studies of nonpharmacologic treatment of mild cognitive impairment (part 1 of 2)

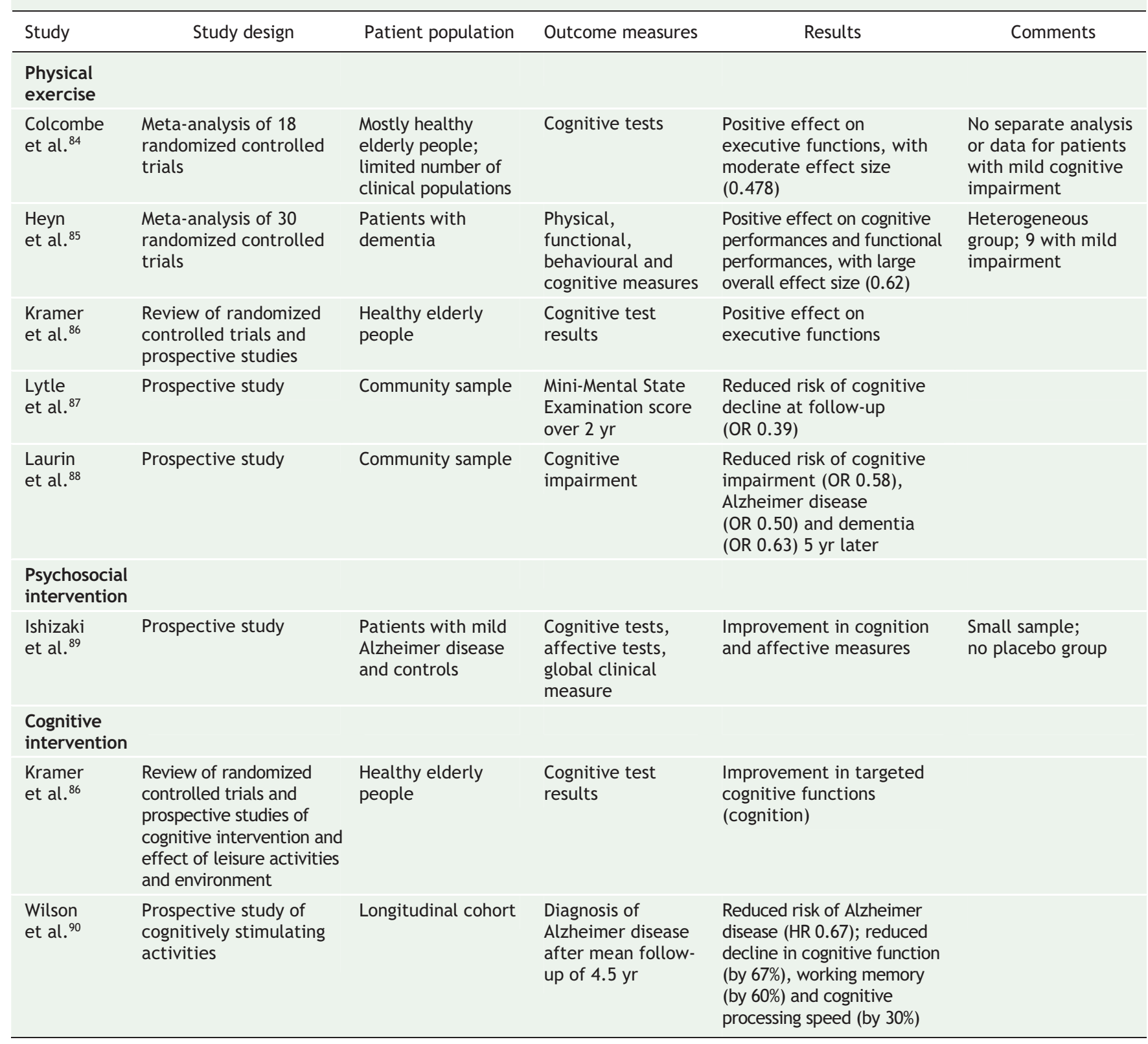




\section{The case revisited}

In the case described at the beginning of this review, Mr. W would meet the criteria for mild cognitive impairment. This is because there are subjective complaints of memory loss from both Mr. W and his family, and he has objective short-term memory loss with preserved daily function. Mr. W was administered the Mini-Mental State Examination as a brief cognitive test to confirm the objective memory loss. Brief cognitive testing with the Montréal Cognitive Assessment or DemTect might reveal even further clear evidence of cognitive impairment. If full neuropsychological testing is available, it would also serve to better document objective memory impairment, assess which other cognitive domains are involved and provide a baseline for the future. Such neuropsychologi- cal testing is by no means obligatory, and most family physicians would be content to follow the patient's progress with annual re-examination.

A patient with mild cognitive impairment such as Mr. W should probably have the same set of blood work as would be ordered for a patient with dementia, although there is currently no literature that speaks to this question in mild cognitive impairment. Mr. W's diagnostic workup would include the laboratory tests currently being used for patient with early dementia (complete blood count, and measurement of thyroid stimulating hormone, vitamin $\mathrm{B}_{12}$, serum calcium and electrolytes). Mr. W has hypertension as a vascular risk factor, but he has never had a transient ischemic attack or stroke. It would be appropriate in this case to perform structural imaging with computed tomography to evaluate possible con-

Table 2: Studies of nonpharmacologic treatment of mild cognitive impairment (part 2 of 2)

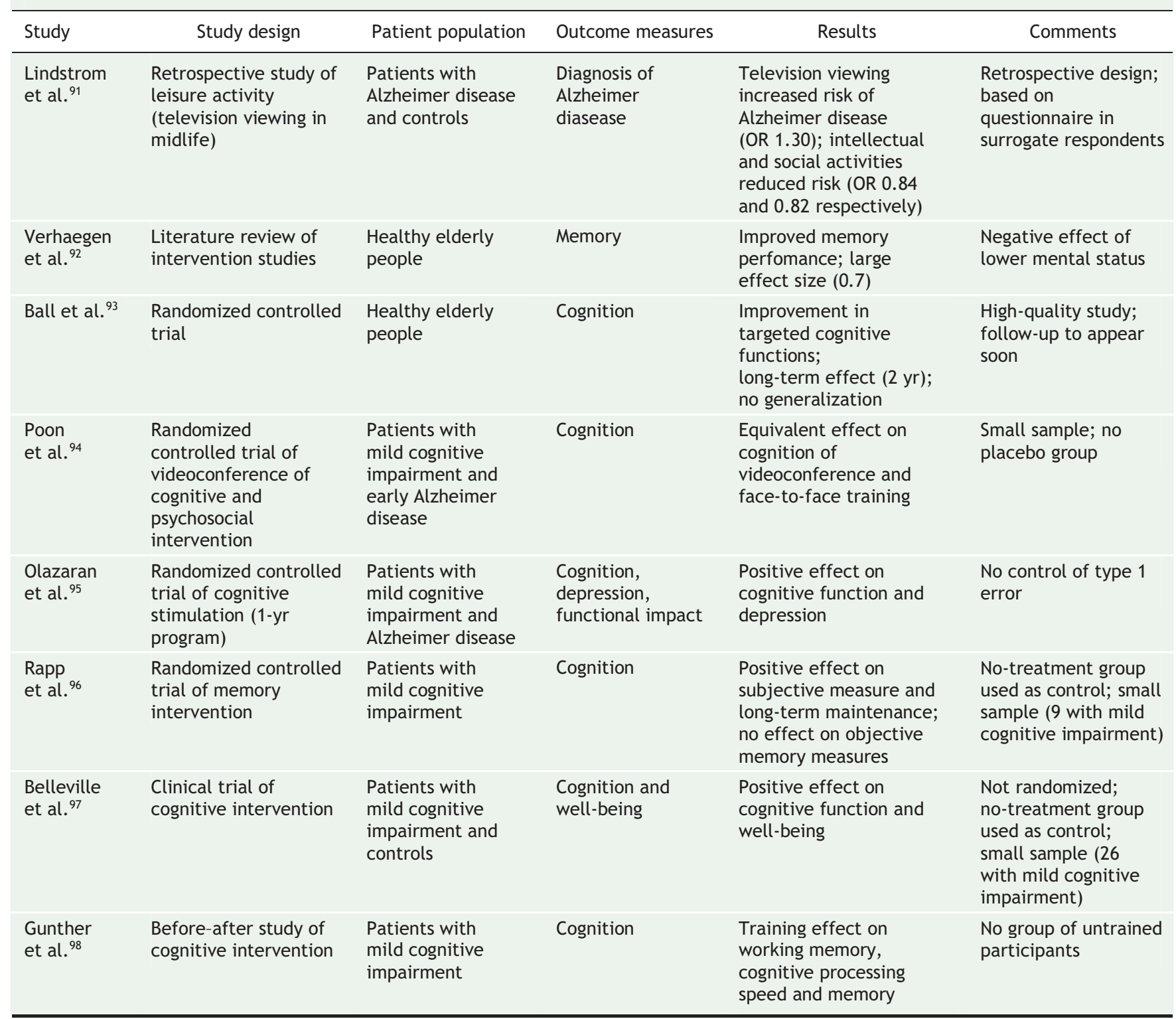


Table 3: Classes of drugs that have shown no benefit* on primary outcome measures for the prevention of progression to dementia in patients with mild cognitive impairment

\begin{tabular}{|c|c|c|c|c|c|}
\hline Drug class & Study & $\begin{array}{l}\text { No. of } \\
\text { patients }\end{array}$ & Outcome & $\begin{array}{l}\text { Quality } \\
\text { of study† }\end{array}$ & Comments \\
\hline \multicolumn{6}{|l|}{ Cholinesterase inhibitors } \\
\hline Rivastigmine & $\begin{array}{l}\text { Feldman } \\
\text { et al. }{ }^{121}\end{array}$ & 1018 & $\begin{array}{l}\text { No significant effect } \\
\text { on primary outcome }\end{array}$ & $5 / 5$ & $\begin{array}{l}\text { Analyses performed according to intention-to- } \\
\text { treat principle; rate of adverse events and } \\
\text { discontinuation higher in treatment group }\end{array}$ \\
\hline Rofecoxib & Thal et al. ${ }^{123}$ & 1457 & $\begin{array}{l}\text { No significant effect } \\
\text { on primary outcome }\end{array}$ & $5 / 5$ & $\begin{array}{l}\text { Analyses performed according to intention-to- } \\
\text { treat principle; rate of adverse events and } \\
\text { discontinuation did not differ between groups }\end{array}$ \\
\hline $\begin{array}{l}\text { Estrogen replacement } \\
\text { therapy }\end{array}$ & $\begin{array}{l}\text { Shumaker } \\
\text { et al. }{ }^{124}\end{array}$ & 4532 & $\begin{array}{l}\text { No significant effect } \\
\text { on primary outcome }\end{array}$ & $5 / 5$ & $\begin{array}{l}\text { Increased risk of dementia in treatment } \\
\text { group }\end{array}$ \\
\hline \multicolumn{6}{|l|}{ Other } \\
\hline Ginkgo biloba & $\begin{array}{l}\text { Van Dongen } \\
\text { et al. }{ }^{125}\end{array}$ & 214 & $\begin{array}{l}\text { No significant effect } \\
\text { on primary outcome }\end{array}$ & $5 / 5$ & $\begin{array}{l}\text { Analyses performed according to intention-to- } \\
\text { treat principle; slightly more adverse events } \\
\text { and discontinuations in treatment group }\end{array}$ \\
\hline
\end{tabular}

Adapted, with permission, from Massoud et al. ${ }^{8}$

*Either in terms of clinically meaningful symptomatic benefit or prevention of progression to dementia.

tQuality of study was rated according to the score described in Jadad et al. ${ }^{126}$

tributing cerebrovascular disease. Even if the scan shows some silent cerebral infarcts, Mr. W's diagnosis of mild cognitive impairment would not change, but stronger motivation would exist to aggressively control his vascular risk factors.

Mr. W should be counselled that he has mild cognitive impairment and is therefore at high risk for progression to dementia over the coming years (from half to three-quarters of such patients seen in memory clinics go on to have dementia over Io years). It is not advisable to falsely reassure him that he is normal. At the same time, there exists a real chance that his condition will not progress to dementia, and there is thus some room for optimism. The prognosis is not clear, and there are no current widely available means of establishing a prognosis. Therefore, annual clinical reassessment should be recommended.

Treatment strategies should be discussed. Exercise and engagement in stimulating cognitive activities should be encouraged, both with the hope of preserving memory and as part of a healthy lifestyle for a person with vascular risk factors. The importance of sleep and managing stress should be reviewed, and Mr. W should be advised to stop the use of diazepam at night. He should be encouraged to continue with rigorous blood pressure control as an important element of memory preservation over the coming years. No other specific pharmacologic therapy should be undertaken at this juncture.

\section{Conclusion}

Physicians will increasingly see elderly patients with mild memory loss, and learning an approach to diagnosing states such as mild cognitive impairment is now warranted. Family physicians should be familiar with the criteria for mild cognitive impairment and start to use them in practice. A review of the literature provides evidence that leisure activities, cognitive stimulation and physical activity should be promoted as part of a healthy lifestyle in elderly people and those with mild cognitive impairment. Vascular risk factors should be treated optimally in these people as well. No other specific therapies can yet be recommended, or supported as having adequate demonstration of efficacy.

It is our hope that, in the future, asymptomatic people will have their Alzheimer disease detected and diagnosed long before symptoms appear, much as we currently screen for diabetes by measuring serum glucose measurements, long before diabetic symptoms occur. In this future scenario, the utility of a clinically heterogeneous label such as mild cognitive impairment may well disappear. In the meantime, this clinical label aids physicians and empowers patients and has a place in the general physician's clinical knowledge base. 
This article has been peer reviewed.

Competing interests: Howard Chertkow has served on the advisory boards of Pfizer Canada, Neurochem Inc. and Lundbeck Canada, has received speaker fees from Pfizer Canada and Lundbeck Canada, has received research grants from Pfizer Canada and has served as a consultant to NeuroTrax. Ziad Nasreddine has been a consultant to and program organizer for Pfizer, has served on the advisory boards of and received speaker fees from Pfizer, Novartis and Janssen-Ortho Inc., and has received research grants from Novartis and Janssen-Ortho Inc., Neurochem, Myriad and Sanofi-Aventis. Fadi Massoud has served on the advisory boards of and has received speaker fees and research funds from Janssen-Ortho Inc., Lundbeck Canada, Novartis and Pfizer. Christian Bocti has received speaker fees from Janssen Ortho Inc. and Pfizer Canada. Morris Freedman has served on the advisory boards of Pfizer, Janssen-Ortho Inc., Novartis and Wyeth, has received speaker fees from Pfizer, Janssen-Ortho Inc., Novartis and Lundbeck Canada and has received research grants from Pfizer, Lundbeck Canada and Eli Lilly. Howard Bergman has received research grants from Pfizer and Novartis. Howard Chertkow is the senior author and Ziad Nasreddine is the lead author of the Montréal Cognitive Assessment, a copyrighted test that is freely available to physicians at www.mocatest.org.

Details of competing interests declared by participants in the Third Canadian Consensus Conference on the Diagnosis and Treatment of Dementia appear in Appendix 3 of the introductory article ${ }^{6}$ (available online at www.cmaj.ca/cgi/content/full/178/3/316/DC2).

Contributors: Howard Chertkow, Fadi Massoud, Ziad Nasreddine and Sylvie Belleville drafted the article, and Christian Bocti, Yves Joanette and Howard Bergman provided an analysis of the literature. All of the authors contributed to the conception and design of the review, revised the manuscript critically for important intellectual content and approved the final version submitted for publication.

Acknowledgements: We thank the clinical staff of the Jewish General Hospital Memory Clinic for their cooperation. We also thank Shelley Solomon and Chris Hosein for superb administrative assistance.

This work was supported by a Chercheur-Boursier National Award to Howard Chertkow from the Fonds de la recherche en santé du Québec and a grant from the Canadian Institutes of Health Research awarded to Howard Chertkow and Howard Bergman.

Editor's Note: The background papers with supporting evidence for the recommendations from the Third Canadian Consensus Conference on the Diagnosis and Treatment of Dementia were published in the October 2007 issue of Alzheimer's and Dementia and are available at www.alzheimersanddementia.org. These articles are also freely available at www.cccdtd.ca (through agreement with Elsevier).

\section{REFERENCES}

I. Jonker C, Geerlings MI, Schmand B. Are memory complaints predictive for dementia? A review of clinical and population-based studies. Int J Geriatr Psychiatry 2000;15:983-9I.

2. Hanninen T, Hallikainen M, Tuomainen S, et al. Prevalence of mild cognitive impairment: a population-based study in elderly subjects. Acta Neurol Scand 2002; I06:I48-54.

3. Heads Up for Healthier Brains media kit: poll summary sheet. Toronto: Alzheimer Society of Canada; 2007. Available: www.alzheimer.ca/english/media /headsupo7-pollsummary.htm (accessed 2008 Apr 9).

4. CSHA. The incidence of dementia in Canada. The Canadian Study of Health and Aging Working Group. Neurology 2000;55:66-73.

5. Goldstein LB, Adams R, Alberts MJ, et al. Primary prevention of ischemic stroke: a guideline from the American Heart Association/American Stroke Association Stroke Council - cosponsored by the Atherosclerotic Peripheral Vascular Disease Interdisciplinary Working Group; Cardiovascular Nursing Council; Clinical Cardiology Council; Nutrition, Physical Activity, and Metabolism Council; and the Quality of Care and Outcomes Research Interdisciplinary Working Group: the American Academy of Neurology affirms the value of this guideline. Stroke 2006;37: I583-633.

6. Chertkow H. Diagnosis and treatment of dementia: introduction. Introducing a series based on the Third Canadian Consensus Conference on the Diagnosis and Treatment of Dementia. CMAJ 2008;178:316-2I.

7. Chertkow $\mathrm{H}$, Nasreddine $\mathrm{Z}$, Joanette $\mathrm{Y}$, et al. Mild cognitive impairment and cogni- tive impairment, no dementia: Part A, concept and diagnosis. Alzheimers Dement 2007;3:266-82.

8. Massoud F, Belleville S, Bergman $\mathrm{H}$, et al. Mild cognitive impairment and cognitive impairment, no dementia: Part B, therapy. Alzheimers Dement 2007;3:283-9I.

9. McKhann G, Drachman D, Folstein M, et al. Clinical diagnosis of Alzheimer's disease: report of the NINCDS-ADRDA Work Group under the auspices of Department of Health and Human Services Task Force on Alzheimer's Disease. Neurology i984;34:939-44.

Io. Feldman HH, Jacova C, Robillard A, et al. Diagnosis and treatment of dementia: 2. Diagnosis. CMAJ 2008;178:825-36.

II. Salthouse TA. Theoretical perspectives on cognitive aging. Hillsdale (NJ): Lawrence Erlbaum Associates; I991. p. 438.

I2. Sliwinski M, Lipton RB, Buschke H, et al. The effects of preclinical dementia on estimates of normal cognitive functioning in aging. J Gerontol B Psychol Sci Soc Sci I996;51:217-25.

13. Bennett DA, Schneider JA, Arvanitakis Z, et al. Neuropathology of older persons without cognitive impairment from two community-based studies. Neurology 2006;66:1837-44.

I4. Kaufman DW, Kelly JP, Rosenberg L, et al. Recent patterns of medication use in the ambulatory adult population of the United States: the Slone survey. JAMA 2002;287:337-44.

I5. Tuokko H, Frerichs RJ. Cognitive impairment with no dementia (CIND): longitudinal studies, the findings and the issues. Clin Neuropsychol 2000; I4:504-25.

I6. Graham JE, Rockwood K, Beattie BL, et al. Prevalence and severity of cognitive impairment with and without dementia in an elderly population. Lancet I997;349:1793-6.

17. Ebly EM, Hogan DB, Parhad IM. Cognitive impairment in the nondemented elderly. Results from the Canadian Study of Health and Aging. Arch Neurol I995;52:612-9.

I8. Tuokko H, Frerichs R, Graham J, et al. Five-year follow-up of cognitive impairment with no dementia. Arch Neurol 2003;60:577-82.

I9. Feldman H, Levy AR, Hsiung GY, et al. A Canadian cohort study of cognitive impairment and related dementias (ACCORD): study methods and baseline results. Neuroepidemiology 2003;22:265-74.

20. Smith $\mathrm{AD}$, Jobst $\mathrm{K}$. Use of structural imaging to study the progression of $\mathrm{Alz}$ heimer's disease. Br Med Bull I996;52: 575-86.

2I. Petersen RC, Smith GE, Waring SC, et al. Mild cognitive impairment: clinical characterization and outcome. Arch Neurol 1999;56:303-8.

22. Petersen RC, Stevens JC, Ganguli M, et al. Practice parameter: early detection of dementia: mild cognitive impairment (an evidence-based review). Report of the Quality Standards Subcommittee of the American Academy of Neurology. Neurology 200I;56:1133-42.

23. Petersen RC, Smith GE, Ivnik RJ, et al. Apolipoprotein E status as a predictor of the development of Alzheimer's disease in memory-impaired individuals [published erratum in JAMA I995;274:538]. JAMA I995;273:1274-8.

24. Hachinski V. Preventable senility: a call for action against the vascular dementias. Lancet $1992 ; 340: 645^{-8}$

25. Hachinski V. Vascular dementia: a radical redefinition. Dementia 1994;5:130-2.

26. O'Brien JT, Erkinjuntti T, Reisberg B, et al. Vascular cognitive impairment. Lancet Neurol 2003;2:89-98.

27. Rockwood K, Davis H, MacKnight C, et al. The Consortium to Investigate Vascular Impairment of Cognition: methods and first findings. Can J Neurol Sci 2003;30:237-43.

28. Fisk JD, Merry HR, Rockwood K. Variations in case definition affect prevalence but not outcomes of mild cognitive impairment. Neurology 2003;61:1179-84.

29. Gauthier S, Touchon J. Mild cognitive impairment is not a clinical entity and should not be treated. Arch Neurol 2005;62:1164-6.

30. Petersen RC. Aging, mild cognitive impairment, and Alzheimer's disease. Neurol Clin 2000;18:789-805.

3I. Petersen RC. Mild cognitive impairment: transition between aging and Alzheimer's disease. Neurologia 2000;15:93-10I.

32. Blacker D. Mild cognitive impairment - no benefit from vitamin E, little from donepezil. N Engl J Med 2005;352:2439-4I.

33. Visser PJ, Verhey FR, Ponds RW Distinction between preclinical Alzheimer's disease and depression. J Am Geriatr Soc 2000;48:479-84.

34. Artero S, Touchon J., Ritchie K. Disability and mild cognitive impairment: a longitudinal population-based study. Int J Geriatr Psychiatry 2001;16:1092-7.

35. Galvin JE, Roe CM, Powlishta KK, et al. The AD8: a brief informant interview to detect dementia. Neurology 2005;65:559-64.

36. Lautenschlager NT, Riemenschneider M, Drzezga A, et al. Primary degenerative mild cognitive impairment: study population, clinical, brain imaging and biochemical findings. Dement Geriatr Cogn Disord 2001;12:379-86.

37. Petersen RC, Smith GE, Waring SC, et al. Mild cognitive impairment: clinical characterization and outcome. Arch Neurol 1999;56:303-8.

38. Kalbe E, Kessler J, Calabrese P, et al. DemTect: a new, sensitive cognitive screening test to support the diagnosis of mild cognitive impairment and early dementia. Int J Geriatr Psychiatry 2004;19:136-43.

39. Nasreddine ZS, Phillips NA, Bedirian V, et al. The Montreal Cognitive Assessment, MoCA: a brief screening tool for mild cognitive impairment. J Am Geriatr Soc 2005:53:695-9.

40. Bennett DA, Schneider JA, Bienias JL, et al. Mild cognitive impairment is related to Alzheimer disease pathology and cerebral infarctions. Neurology 2005;64:834-4I.

4I. Grundman M, Petersen RC, Morris JC, et al. ADSC Cooperative Study. Rate of dementia of the Alzheimer type (DAT) in subjects with mild cognitive impairment [abstract]. Neurology I996;46:A403. 
42. Daly E, Zaitchik D, Copeland M, et al. Predicting conversion to Alzheimer disease using standardized clinical information. Arch Neurol 2000;57:675-80.

43. Frisoni GB, Padovani A, Wahlund LO. The predementia diagnosis of Alzheimer disease. Alzheimer Dis Assoc Disord 2004;18:5I-3.

44. Bennett DA. Mild cognitive impairment. Clin Geriatr Med 2004;20:15-25.

45. Bennett DA, Wilson RS, Schneider JA, et al. Natural history of mild cognitive impairment in older persons. Neurology 2002;59:198-205

46. Dubois B, Albert ML. Amnestic MCI or prodromal Alzheimer's disease? Lancet Neurol 2004;3:246-8.

47. Morris JC, Storandt M, Miller JP, et al. Mild cognitive impairment represents earlystage Alzheimer disease. Arch Neurol 200I;58:397-405

48. Ritchie K, Leibovici D, Ledesert B, et al. A typology of sub-clinical senescent cognitive disorder. BrJ Psychiatry 1996;168:470-6.

49. Visser PJ, Kester A, Jolles J, et al. Ten-year risk of dementia in subjects with mild cognitive impairment. Neurology 2006;67:120I-7.

50. Chertkow H, Verret L, Bergman H, et al. Predicting progression to dementia in elderly subjects with mild cognitive impairment - a multidisciplinary approach. Proceedings of the 200r Contemporary Clinical Issues Plenary Session. 53rd Annual Meeting of the American Academy of Neurology; 200I May 5-II; Philadelphia.

51. Chertkow H. High and low tech prediction of progression to Alzheimer disease in mild cognitive impairment. Neurobiol Aging 2004;25:S5

52. Chertkow HM, Bergman H, Bocti C, et al. Amnestic mild cognitive impairment in a referral population-a non-progressing subgroup exists on long-term follow-up [abstract 04-04-03]. Proceedings of the ICAD-Alzheimer's Association Ioth International Conference on Alzheimer's Disease and Related Disorders; 2006 July; Madrid.

53. Bennett DA. Update on mild cognitive impairment. Curr Neurol Neurosci Rep 2003:3:379-84.

54. Saxton J, Lopez OL, Ratcliff G, et al. Preclinical Alzheimer disease: neuropsychological test performance I. 5 to 8 years prior to onset. Neurology 2004;63:234I-7.

55. Gauthier S, Reisberg B., Zaudig M., et al. Mild Cognitive Impairment. Lancet 2006; 367:1262-70.

56. Chertkow H. Mild cognitive Impairment and very early stage Alzheimer's disease. In: Gauthier S, ed. Clinical Diagnosis and management of Alzheimer's disease, Third Edition. London: Informa UK; 2006:205-22I.

57. Andreasen N, Minthon L, Vanmechelen E, et al. Cerebrospinal fluid tau and Abeta42 as predictors of development of Alzheimer's disease in patients with mild cognitive impairment. Neurosci Lett 1999;273:5-8.

58. Bartres-Faz D, Junque C, Lopez-Alomar A, et al. Neuropsychological and genetic differences between age-associated memory impairment and mild cognitive impairment entities. J Am Geriatr Soc 200I;49:985-90.

59. Lehmann M, Gottfries CG, Regland B. Identification of cognitive impairment in the elderly: Homocysteine is an early marker. Dement Geriatr Cogn Disord I999; IO:I2-20.

6o. Corrada M, Kawas C. Plasma total cholesterol, LDL, HDL levels and the risk of Alzheimer Disease: the Baltimore Longitudinal Study of Aging [abstract]. Neurology 2002;58:A1o6.

6r. Yaffe K, Simonsick E, Launer L, et al. Inflammatory markers and cognitive decline in well-functioning elders: the Health ABC Study [abstract]. Neurology 2002;58:Aro6.

62. Graves $\mathrm{AB}$, Bowen JD, Rajaram L, et al. Impaired olfaction as a marker for cognitive decline: interaction with apolipoprotein E epsilon4 status. Neurology 1999;53:I480-7.

63. Djordjevic J, Jones-Gotman M, De Sousa K, et al. Olfaction in patients with mild cognitive impairment and Alzheimer's disease. Neurobiol Aging 2008;29:693-706.

64. Schipper HM, Chertkow H, Mehindate K, et al. Evaluation of heme oxygenase-I as a systemic biological marker of sporadic AD. Neurology 2000;54:1297-304.

65. Jack CR, Petersen RC, Xu Y, et al. Rate of medial temporal lobe atrophy in typical aging and Alzheimer's disease. Neurology 1998;51:993-9.

66. Fox NC. Increased rates of atrophy in early and preclinical AD: studies with registration of serial MRI. Neurobiol Aging 2000;2I:S74

67. Jack CR Jr, Petersen RC, Xu Y, et al. Rates of hippocampal atrophy correlate with change in clinical status in aging and AD. Neurology 2000;55:484-9.

68. De Leon MJ, Convit A, et al. Longitudinal measures of hippocampal formation pathology and CSF measures of phospho-tau and amyloid beta: early markers for Alzheimer disease. Seventh International Geneva/Springfield Symposium on Advances in Alzheimer Therapy; 2002; Geneva.

69. De Leon MJ, Convit A, Wolf OT, et al. Prediction of cognitive decline in normal elderly subjects with 2-[(I8)F]fluoro-2-deoxy-D-glucose/poitron-emission tomography (FDG/PET). Proc Natl Acad Sci U S A 200I;98:10966-7I.

70. Reiman EM, Caselli RJ, Yun LS, et al. Preclinical evidence of Alzheimer's disease in persons homozygous for the epsilon 4 allele for apolipoprotein E. $N$ Engl J Med I996;334:752-8.

7I. McKelvey R, Bergman H, Stern J, et al. Lack of prognostic significance of SPECT abnormalities in non-demented elderly subjects with memory loss. Can J Neuro Sci I999;26:23-8.

72. Johnson KA, Jones K, Holman BL, et al. Preclinical prediction of Alzheimer's disease using SPECT. Neurology I998;50:1563-71.

73. Kantarci K, Jack CR Jr, Xu YC, et al. Regional metabolic patterns in mild cognitive impairment and Alzheimer's disease: a IH MRS study. Neurology 2000:55:210-7.

74. Nordberg A. PET activation in MCI and AD patients. Proceedings of the Seventh Annual Springfield/Geneva Symposium on Advances in Alzheimer Therapy; 2002, Geneva.

75. Bookheimer SY, Strojwas M, et al. Patterns of brain activation in people at risk for Alzheimer's disease. N Engl J Med 2000;343:450-6.

76. Nordberg A. PET imaging of amyloid in Alzheimer's disease. Lancet Neurol 2004; 3:519-27.
77. Mintun MA, Larossa GN, Sheline YI, et al. [IIC]PIB in a nondemented population potential antecedent marker of Alzheimer disease. Neurology 2006;67:446-52.

78. DeKosky ST, Mathis CA, Price JC, et al. Pattern of amyloid plaque deposition with Pittsburgh coumpound-B (PIB) in mild cognitive impairment [abstract $\mathrm{O}_{3}$-06-08]. Proceedings of the ICAD-Alzheimer's Association Ioth International Conference on Alzheimer's Disease and Related Disorders; 2006; Madrid.

79. Tierney MC, Szalai JP, Snow WG, et al. The prediction of Alzheimer disease. The role of patient and informant perceptions of cognitive deficits. Arch Neurol I996;53:423-7 .

8o. Devanand DP, Folz M, Gorlyn M, et al. Questionable dementia: clinical course and predictors of outcome. JAm Geriatr Soc I997;45:32I-8.

8I. Devanand DP, Michaels-Marston KS, Liu X, et al. Olfactory deficits in patients with mild cognitive impairment predict Alzheimer's disease at follow-up. Am J Psychiatry 2000;157:1399-405.

82. Albert MS, Moss MB, Tanzi R, et al. Preclinical prediction of AD using neuropsy chological tests. J Int Neuropsychol Soc 2001;7:631-9.

83. Chertkow $\mathrm{H}$. Emerging pharmacological therapies for mild cognitive impairment. In: Tuokko HA, Hultsch DF, editors. Mild cognitive impairment: international perspectives. New York: Taylor \& Francis; 2006. p. 217-43

84. Colcombe S, Kramer AF. Fitness effects on the cognitive function of older adults: meta-analytic study. Psychol Sci 2003;I4:125-30.

85. Heyn P, Abreu BC, Ottenbacher KJ. The effects of exercise training on elderly persons with cognitive impairment and dementia: a meta-analysis. Arch Phys Med Rehabil 2004;85:I694-704.

86. Kramer AF, Bherer L, Colcombe SJ, et al. Environmental influences on cognitive and brain plasticity during aging. J Gerontol A Biol Sci Med Sci 2004;59:M940-57.

87. Lytle ME, Vander Bilt J, Pandav RS, et al. Exercise level and cognitive decline: the MoVIES project. Alzheimer Dis Assoc Disord 2004;18:57-64.

88. Laurin D, Verreault R, Lindsay J, et al. Physical activity and risk of cognitive impairment and dementia in elderly persons. Arch Neurol 2001;58:498-504.

89. Ishizaki J, Meguro K, Ohe K, et al. Therapeutic psychosocial intervention for elderly subjects with very mild Alzheimer disease in a community: the Tajiri Project. Alzheimer Dis Assoc Disord 2002;16:26I-9.

9o. Wilson RS, Mendes De Leon CF, Barnes LL, et al. Participation in cognitively stimulating activities and risk of incident Alzheimer disease. JAMA 2002;287:742-8.

9I. Lindstrom HA, Fritsch T, Petot G, et al. The relationships between television viewing in midlife and the development of Alzheimer's disease in a case-control study. Brain Cogn 2005; 58:157-65.

92. Verhaeghen P, Marcoen A, Goossens L. Improving memory performance in the aged through mnemonic training: a meta-analytic study. Psychol Aging 1992;7: 242-5I.

93. Ball K, Berch DB, Helmers KF, et al. Effects of cognitive training interventions with older adults: a randomized controlled trial. JAMA 2002;288:227I-8I.

94. Poon P, Hui E, Dai D, et al. Cognitive intervention for community-dwelling older persons with memory problems: telemedicine versus face-to-face treatment. Int ) Geriatr Psychiatry 2005;20:285-6.

95. Olazaran J, Muniz R, Reisberg B, et al. Benefits of cognitive-motor intervention in MCI and mild to moderate Alzheimer disease. Neurology 2004;63:2348-53.

96. Rapp S, Brenes G, Marsh AP. Memory enhancement training for older adults with mild cognitive impairment: a preliminary study. Aging Ment Health 2002;6:5-II.

97. Belleville S, Gilbert B, Fontaine F, et al. Improvement of episodic memory in persons with mild cognitive impairment and healthy older adults: evidence from a cognitive intervention program. Dement Geriatr Cogn Disord 2006;22:486-99.

98. Gunther VK, Schafer P, Holzner BJ, et al. Long-term improvements in cognitive performance through computer-assisted cognitive training: a pilot study in a residential home for older people. Aging Ment Health 2003;7:200-6.

99. Bliwise DL. Is sleep apnea a cause of reversible dementia in old age? J Am Geriat Soc 1996;44:1407-9.

Iоo. Boeve BF, Silber MH, Ferman TJ, et al. Association of REM sleep behavior disorder and neurodegenerative disease may reflect an underlying synucleinopathy. Mov Disord 2001; 6:622-30.

IoI. Riemann D, Hohagen F, Bahro M, et al. Cholinergic neurotransmission, REM sleep and depression. J Psychosom Res 1994;38(Suppl I):15-25

I02. Adler G, Bramesfeld A, Jajcevic A. Mild cognitive impairment in old-age depression is associated with increased EEG slow-wave power. Neuropsychobiology I999;40:218-22

I03. Alexopoulos GS. Heterogeneity and comorbidity in dementia-depression syndromes [editorial]. Int J Geriatr Psychiatry I991;6:125-7.

I04. Coen RF, Kirby M, Swanwick GR, et al. Distinguishing between patients with depression or very mild Alzheimer's disease using the delayed-word-recall test. Dement Geriatr Cogn Disord I997;8:244-7.

I05. Reischies FM, Neu P. Comorbidity of mild cognitive disorder and depression - a neuropsychological analysis. Eur Arch Psychiatry Clin Neurosci 2000;250:186-93.

Io6. Alexopoulos GS, Meyers B, Young R, et al. The course of geriatric depression with "reversible dementia": a controlled study. Am J Psychiatry I993;150:1693-9.

I07. Fratiglioni L, Wang HX, Ericsson K, et al. Influence of social network on occurrence of dementia: a community-based longitudinal study. Lancet 2000;355:1315-9.

Io8. Willis SL, Tennstedt SL, Marsiske M, et al. Long-term effects of cognitive training on everyday functional outcomes in older adults. JAMA 2006;296:2805-I4.

I09. Wilson RS, Beckett LA, Barnes LL, et al. Individual differences in rates of change in cognitive abilities of older persons. Psychol Aging 2002;17:179-93.

Iro. Ott A, Stolk RP, van Harskamp F, et al. Diabetes mellitus and the risk of dementia the Rotterdam Study. Neurology I999;53:1937-42.

III. Yaffe K, Blackwell T, Kanaya AM, et al. Diabetes, impaired fasting glucose, and development of cognitive impairment in older women. Neurology 2004;63:658-63. 
II2. Yaffe K, Kanaya A, Lindquist K, et al. The metabolic syndrome, inflammation, and risk of cognitive decline. JAMA 2004;292:2237-42.

II3. Elias MF, Elias PK, Sullivan LM, et al. Lower cognitive function in the presence of obesity and hypertension: the Framingham heart study. Int J Obes Relat Metab Disord 2003;27:260-8.

II4. Forette F, Seux ML, Staessen JA, et al. Prevention of dementia in randomised double-blind placebo-controlled Systolic Hypertension in Europe (Syst-Eur) trial. Lancet I998; 352:1347-5I.

II5. Tzourio C, Anderson C, Chapman N, et al. Effects of blood pressure lowering with perindopril and indapamide therapy on dementia and cognitive decline in patients with cerebrovascular disease. Arch Intern Med 2003;163:1069-75.

II6. Starr JM, Whalley LJ, Deary IJ. The effects of antihypertensive treatment on cognitive function: results from the HOPE study. J Am Geriatr Soc 1996;44:4II-5.

II7. Shepherd J, Blauw GJ, Murphy MB, et al. Pravastatin in elderly individuals at risk of vascular disease (PROSPER): a randomised controlled trial. Lancet 2002;360:I623-30.

II8. Collins R, Armitage J, Parish S, et al. Effects of cholesterol-lowering with simvastatin on stroke and other major vascular events in 20536 people with cerebrovascular disease or other high-risk conditions. Lancet 2004;363:757-67.

II9. Salloway S, Ferris S, Kluger A, et al. Efficacy of donepezil in mild cognitive impairment: a randomized placebo-controlled trial. Neurology 2004;63:65I-7.

I20. Petersen RC, Thomas RG, Grundman M, et al. Vitamin E and donepezil for the treatment of mild cognitive impairment. N Engl J Med 2005;352:2379-88.

I2I. Feldman $\mathrm{HH}$, Ferris S, Winblad B, et al. Effect of rivastigmine on delay to diagnosis of Alzheimer's disease from mild cognitive impairment: the InDDEx study. Lancet Neurol 2007;6:50I-I2.

I22. Loy C, Schneider L. Galantamine for Alzheimer's disease and mild cognitive impairment. Cochrane Database Syst Rev 2006; (I):CDooI747.

I23. Thal LJ, Ferris SH, Kirby L, et al. A randomized, double-blind, study of rofecoxib in patients with mild cognitive impairment. Neuropsychopharmacology 2005;30:1204-I5.

I24. Shumaker SA, Legault C, Rapp SR, et al. Estrogen plus progestin and the incidence of dementia and mild cognitive impairment in postmenopausal women: the Women's Health Initiative Memory Study: a randomized controlled trial. JAMA 2003;289:265I-62.

I25. Van Dongen M, van Rossum E, Kessels A, et al. Ginkgo for elderly people with dementia and age-associated memory impairment: a randomized clinical trial. J Clin
Epidemiol 2003;56:367-76.

I26. Jadad AR, Moore RA, Carroll D, et al. The quality of reports of randomized clinical trials: Is blinding necessary? Control Clin Trials 1996;17:I-I2

127. Dubois B, Feldman HH, Jacova C, et al. Research criteria for the diagnosis of Alzheimer's disease: revising the NINCDS-ADRDA criteria. Lancet Neurol 2007; 6:734-46.

Correspondence to: Dr. Howard Chertkow, Bloomfield Centre for Research in Aging, Lady Davis Institute for Medical Research, Sir Mortimer B. Davis-Jewish General Hospital, McGill University, Montréal QC $\mathrm{H}_{3} \mathrm{~T}$ IE2; fax 514 340-8925;

howard.chertkow@mcgill.ca

\section{Articles to date in this series}

- Chertkow H. Diagnosis and treatment of dementia: Introduction. Introducing a series based on the Third Canadian Consensus Conference on the Diagnosis and Treatment of Dementia. CMAJ 2008;178:316-21.

- Patterson C, Feightner JW, Garcia A, et al. Diagnosis and treatment of dementia: 1 . Risk assessment and primary prevention of Alzheimer disease. CMA/ 2008;178:548-56.

- Feldman HH, Jacova C, Robillard A, et al. Diagnosis and treatment of dementia: 2. Diagnosis. CMAJ 2008;178:825-36. 